\title{
Immunotoxin D2C7-(scdsFv)-PE38KDEL
}

\author{
National Cancer Institute
}

\section{Source}

National Cancer Institute. Immunotoxin D2C7-(scdsFv)-PE38KDEL. NCI Thesaurus. Code C119739.

A recombinant immunotoxin fusion protein consisting of single-chain variable-region antibody frag ments (scFvs), which contain disulfide stabilized heavy- (Vh) and light- (VI) chain variable regions of the monoclonal antibody D2C7 (D2C7-scdsFv), targeting both the wild-type form (EGFRwt) and the in-frame deletion mutant form (EGFRVIII) of epidermal growth factor receptor (EGFR), and fused, via a 15-amino acid peptide linker to domains II and III of the Pseudomonas exotoxin A (PE38KDEL) (D2C7-(scdsFv)PE38KDEL), with potential antineoplastic activity. Upon intratumoral administration by convection-enhanced delivery, the scFv moiety of immunotoxin anti-EGFR scFv monoclonal antibody fragment immunotoxin D2C7-(scdsFv)-PE38KDEL targets and binds to a specific amino acid epitope present in the extracellular domain of both the EGFRwt and EGFRvIII proteins. This binding facilitates the internalization of the immunotoxin by tumor cells. Inside the cells, the exotoxin portion of the fusion protein binds to translation elong ation factor 2 (EF-2), and deactivates EF-2 through ADP ribosylation. This results in the inhibition of protein synthesis, the induction of apoptosis and a reduction in cell proliferation of EGFRwt/EGFRvIII-expressing tumor cells. Compared to intact IgG antibodies and single-chain antibodies, scFvs are smaller with increased tumor-penetrating capacity which may enhance therapeutic efficacy. The EGFR gene, a transmembrane receptor tyrosine kinase, and its mutant form, EGFRvIII, which contains a deletion of exons 2-7 of the EGFR gene, are frequently amplified and overexpressed in a variety of cancers. KDEL increases the toxin's intracellular retention, thereby enhancing its cytotoxicity. 